\title{
Pavlovian Conditioning
}

National Cancer Institute

\section{Source}

National Cancer Institute. Pavlovian Conditioning. NCI Thesaurus. Code C41215.

A classical conditioning procedures that present different stimuli in temporal proximity (contiguity), but where resulting responses have no reinforcing or aversive consequences. Named after the author of the experiments (Dr. I. Pavlov) in which dogs were conditioned to salivate at the sound of a tone. 